\title{
SYNTHESIS, STRUCTURE, AND MAGNETISM OF HETEROBINUCLEAR COMPLEX $\mathrm{GdCu}(\mathrm{OTf})_{3}(\mathrm{bdmap})_{2}\left(\mathrm{H}_{2} \mathrm{O}\right) \cdot \mathrm{THF}$
}

\author{
Song GaO*, O. Borgmeier and H. Lueken \\ Institut für Anorganische Chemie \\ Rheinisch-Westfälische Technische Hochschule Aachen \\ Prof.-Pirlet-Strasse 1, 52056 Aachen, Germany
}

A new heterobinuclear $\mathrm{Gd}(\mathrm{III})-\mathrm{Cu}(\mathrm{II})$ complex $[\mathrm{GdCu}]=$ $\mathrm{GdCu}(\mathrm{OTf})_{3}(\mathrm{bdmap})_{2}\left(\mathrm{H}_{2} \mathrm{O}\right) \cdot \mathrm{THF}\left(\mathrm{OTf}=\mathrm{SO}_{3} \mathrm{CF}_{3}\right)$ has been prepared by reaction of 1,3-bis(dimethylamino)-2-propanol (bdmapH) with $\mathrm{Cu}\left(\mathrm{OCH}_{3}\right)_{2}$ and lanthanide trillate salt $\mathrm{Gd}(\mathrm{OTf})_{3}$ in a $2: 1: 1$ ratio in THF. Its structure has been determined by single-crystal X-ray diffraction. [GdCu] crystallizes on an orthorhombic lattice, space group $P 2_{1} 2_{1} 2_{1}$ with $Z=4$ and $a=11.023(3) \AA, b=17.555(15) \AA, c=20.212(7) \AA, V=3911(4) \AA^{3}$. For 2194 independent reflections with $I>1 \sigma(I)$, full-matrix least squares refinement with anisotropic thermal parameters for $\mathrm{Gd}, \mathrm{Cu}, \mathrm{S}$, and $\mathrm{O}$ converged to unweighted and weighted $R$ factors of 0.074 and 0.085 , respectively. Gd is coordinated by six $\mathrm{O}$ and two N. Cu is coordinated by two $\mathrm{O}$ and two N. Gd and $\mathrm{Cu}$ are bridged by two alkoxo $\mathrm{O}$ atoms with separation of $3.311(4) \AA$. The magnetic susceptibilities were measured over the temperature range 1.7-20 K at the field range $0.01-0.5 \mathrm{~T}$. The data of [GdCu] at $0.05 \mathrm{~T}$ have been analyzed with the use of a Heisenberg spin Hamiltonian $\hat{H}=-2 J \hat{S}_{\mathrm{Gd}} \cdot \hat{S}_{\mathrm{Cu}}$ giving $g=2.046(2), J=-0.039(3) \mathrm{cm}^{-1}$. This shows that $\mathrm{Gd}-\mathrm{Cu}$ spins are coupled very weakly in the antiferromagnetic manner, though the distance between $\mathrm{Gd}(\mathrm{III})$ and $\mathrm{Cu}(\mathrm{II})$ ions is rather short.

PACS numbers: $36.40 .+d, 61.66 . F n$

\section{Introduction}

In the last decade, several kinds of $\left[\mathrm{Gd}_{x} \mathrm{Cu}_{y}\right]$ heteronuclear complexes were structurally and magnetochemically characterized, for example compounds with clusters: $\left[\mathrm{Gd}_{2} \mathrm{Cu}_{2}\right][1],\left[\mathrm{GdCu}_{2}\right][2,3],\left[\mathrm{Gd}_{2} \mathrm{Cu}_{4}\right][4],\left[\mathrm{GdCu}_{3}\right][5]$, and two-dimensional layers $\left[\mathrm{Gd}_{2} \mathrm{Cu}_{3} \cdot \mathrm{Cu}\right][6,7]$. Up to now, the observed spin-spin coupling between $\mathrm{Gd}(\mathrm{III})$ and $\mathrm{Cu}(\mathrm{II})$ is almost in the ferromagnetic manner with one exception [8]. In this paper the first structurally characterized [GdCu] binuclear complex and its magnetic properties are reported.

* On leave of absence from: Department of Chemistry, Peking University, Beijing 100871, China. 


\section{Experimental section}

\subsection{Synthesis}

Reactions were carried out under argon atmosphere by using standard Schlenk techniques. $1 \mathrm{mmol}$ of $\mathrm{Cu}\left(\mathrm{OCH}_{3}\right)_{2}$ (Aldrich Chemical Co.) was dissolved in $30 \mathrm{ml}$ of dry THF, and $2 \mathrm{mmol}$ of 1,3-bis(dimethylamino)-2-propanol (bdmapH, Aldrich Chemical Co.) were added while stirring. After 2 hours, $1 \mathrm{mmol}$ of $\mathrm{Gd}(\mathrm{OTf})_{3}$ (obtained from $\mathrm{Gd}_{2} \mathrm{O}_{3}$ and IIOTf as described previously $[9,10]$ ) was added to the purple suspension. The mixture was stirred for $12 \mathrm{~h}$ at room temperature to yield a blue solution. The solution was filtered by suction and the solvent was evaporated to $5 \mathrm{ml}$. Blue crystals formed over a period of $5 \mathrm{~d}$ upon adding hexane.

\subsection{Magnetic susceptibility measurements}

Magnetic susceptibility data were collected in the temperature range of 1.7-20 $\mathrm{K}$ at magnetic fields ranging from 0.01-0.5 $\mathrm{T}$ employing the MSPS-5S SQUID magnetometer. The data were corrected for diamagnetic contributions using Pascal's constants.

\section{3. $X$-ray structure determination}

A single crystal of [GdCu] $\left(0.15 \times 0.20 \times 0.33 \mathrm{~mm}^{3}\right)$ was used for crystal data collection on an Enraf-Nonius CAD4 diffractometer using graphite-monochromated Mo $K_{\alpha}$ radiation in the $2 \theta$-scan mode $\left(2 \theta_{\max }=48^{\circ}\right)$. Lattice parameters were determined by least squares refinement of the setting angles of 25 computer-centered reflections in the range of $0.01^{\circ} \leq 2 \theta \leq 48.0^{\circ}$. The data were empirically corrected for Lorentz polarization and absorption. The crystal belongs to the orthorhombic system, the space group being $P 2_{1} 2_{1} 2_{1}$ as indicated by the systematic absences. The structure was solved using direct methods (NRCVAX)[11]. Mydrogen atoms were located in calculated positions $(\mathrm{C}-\mathrm{H}=$ $1.08 \AA$ ). The final refinement (NRCVAX) converged to $R=0.074$ and $R_{\mathrm{w}}=0.085$ by using 2194 independent reflections with $I>1 \sigma(I)$. The maximum residual peak in the last difference Fourier map is $0.94 e \AA^{-3}$.

\section{Results and discussion}

\subsection{Crystal and molecular structure}

The molecular structure of [GdCu] is shown in Fig. 1. Selected bond lengths and bond angles are given in Table. Gd is linked with $\mathrm{Cu}$ through two alkoxo $\mathrm{O}$ atoms of bdmap with a Gd-Cu separation of $3.311(4) \AA$, which is the second shortest $\mathrm{Gd}-\mathrm{Cu}$ distance found in all reported $\left[\mathrm{Gd}_{x} \mathrm{Cu}_{y}\right]$ complexes $[5,12,13]$. $\mathrm{Gd}$ is eightfold coordinated in an irregular manner by two alkoxo $\mathrm{O}$ atoms, three $\mathrm{O}$ atoms of OTf anions, one $\mathrm{O}$ atom of water, and two $\mathrm{N}$ atoms of two bdmap. $\mathrm{Cu}$ is fourfold coordinated by two $\mathrm{N}$ and two $\mathrm{O}$ atoms of two bdmap, forming a slightly $D_{2 d}$ distorted square (distances to the plane: $01,0.15(3) ; 02,-0.13(3)$; $\mathrm{N} 1,-0.13(3) ; \mathrm{N} 2,0.22(4) \AA)$. O12 and O33 of two OTf anions look like two axial 


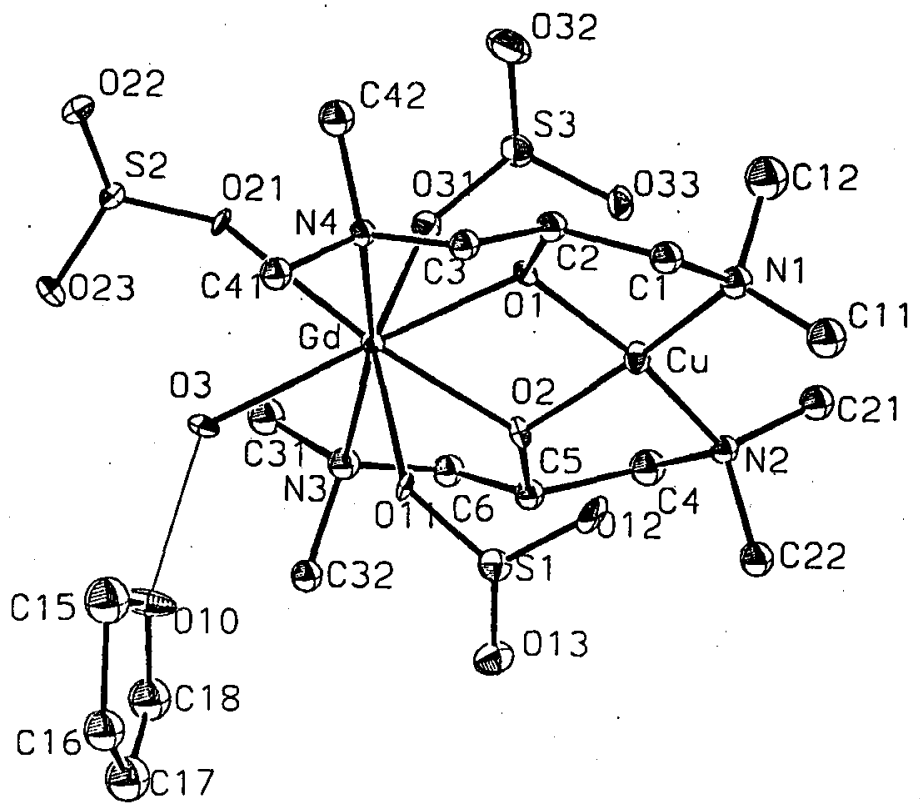

Fig. 1. ORTEP view of the complex [GdCu] and labeling scheme. Fluorine and carbon atoms of the triflate anions are omitted.

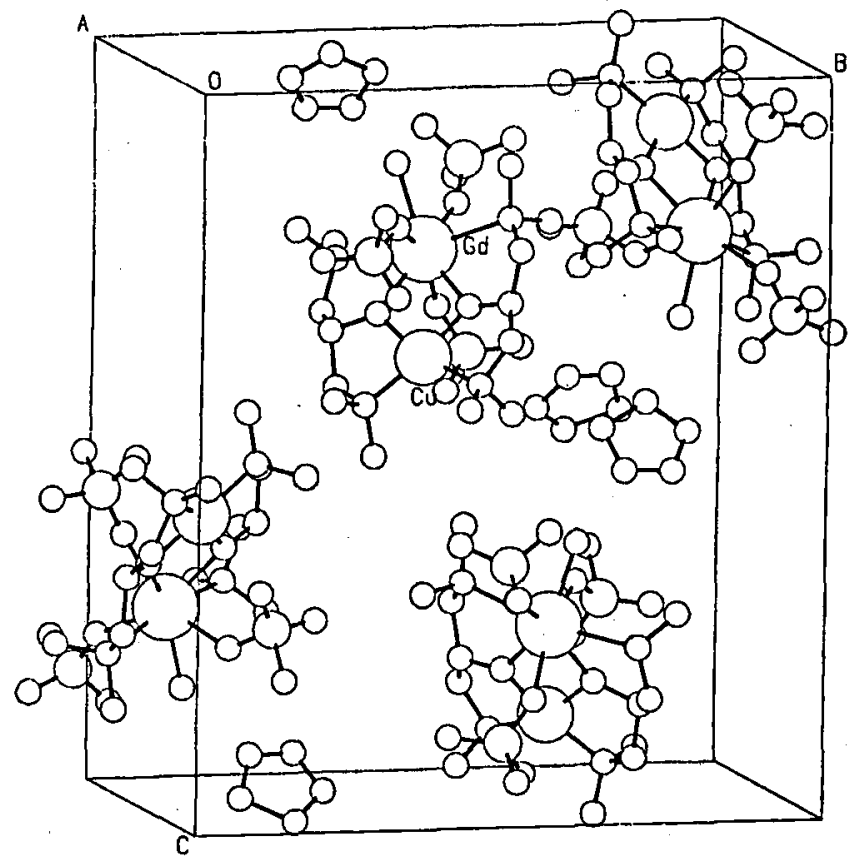

Fig. 2. Schematic view of the unit cell of [GdCu]. 
Selected bond lengths $(\AA)$ and bond angles (deg) for [GdCu].

\begin{tabular}{l|l|l|l|l|l}
\hline \hline \multicolumn{1}{c|}{ Bond } & Lengths & \multicolumn{1}{c|}{ Bond } & Lengths & Bond & \multicolumn{1}{c}{ Lengths } \\
\hline Gd-Cu & $3.311(4)$ & Cu-O2 & $1.892(19)$ & C1-C2 & $1.58(6)$ \\
Gd-O1 & $2.215(20)$ & Cu-N1 & $2.02(3)$ & C3-C2 & $1.54(5)$ \\
Gd-O2 & $2.278(20)$ & Cu-N2 & $2.06(3)$ & O1-C2 & $1.36(4)$ \\
Gd-O3 & $2.418(22)$ & C4-C5 & $1.57(5)$ & O2-C5 & $1.45(4)$ \\
Gd-O11 & $2.411(22)$ & C5-C6 & $1.38(6)$ & S1-O11 & $1.476(22)$ \\
Gd-O21 & $2.477(18)$ & N1-C1 & $1.51(5)$ & S2-O21 & $1.402(19)$ \\
Gd-O31 & $2.42(3)$ & N2-C4 & $1.46(6)$ & S3-O31 & $1.47(3)$ \\
Gd-N3 & $2.62(3)$ & N3-C6 & $1.50(5)$ & O10-C15 & $1.38(7)$ \\
Gd-N4 & $2.71(3)$ & N4-C3 & $1.45(5)$ & O10-C18 & $1.29(6)$ \\
Cu-O1 & $1.914(21)$ & & & & \\
\hline \multicolumn{1}{c}{ Bond } & Angles & Bond & Angles & Bond & Angles \\
\hline O1-Gd-O2 & $67.2(7)$ & O11-Gd-O2 & $74.6(7)$ & O2-Cu-N2 & $83.5(10)$ \\
O1-Gd-O31 & $77.2(9)$ & O11-Gd-O3 & $71.2(7)$ & N1-Cu-N2 & $110.2(13)$ \\
O1-Gd-O11 & $85.6(8)$ & O11-Gd-N4 & $79.1(8)$ & Gd-O1-Cu & $106.4(8)$ \\
O1-Gd-N4 & $63.9(7)$ & O3-Gd-O21 & $68.9(7)$ & Gd-O2-Cu & $104.7(9)$ \\
O31-Gd-O2 & $79.5(8)$ & O3-Gd-N3 & $80.3(9)$ & Gd-O1-C2 & $131.7(19)$ \\
O21-Gd-N4 & $81.2(8)$ & O3-Gd-N4 & $87.9(7)$ & Cu-O1-C2 & $113.9(20)$ \\
N3-Gd-N4 & $168.1(8)$ & O2-Gd-N3 & $63.8(8)$ & Gd-O2-C5 & $127.6(18)$ \\
O31-Gd-O21 & $71.3(8)$ & O1-Cu-O2 & $81.6(9)$ & Cu-O2-C5 & $121.9(17)$ \\
O31-Gd-N3 & $77.0(9)$ & O1-Cu-N1 & $86.5(11)$ & &
\end{tabular}

coordinated atoms towards $\mathrm{Cu}(\mathrm{II})$ with $\mathrm{Cu}-\mathrm{O}$ distances $2.79(2)$ and $2.78(2) \AA$, respectively. The angle of $\mathrm{O} 12-\mathrm{Cu}-\mathrm{O} 33$ is $164^{\circ}$. The atoms $\mathrm{Gd}, \mathrm{Cu}, \mathrm{O} 1, \mathrm{O} 2$ form a perfect plane. $\mathrm{O} 10$ of TIIF is connected with $\mathrm{O} 3$ by a hydrogen bond, the distance between $\mathrm{O} 10$ and $\mathrm{O} 3$ is $2.57 \AA$. Four binuclear units are packed in the unit cell shown in Fig. 2. Between binuclear units, the minimum separations for Gd-Gd, $\mathrm{Gd}-\mathrm{Cu}$, and $\mathrm{Cu}-\mathrm{Cu}$ are $9.598,8.264$, and $8.757 \AA$, respectively.

\subsection{Magnetic properties}

The magnetic susceptibility data (at $0.05 \mathrm{~T}$ ) were fitted to the Curie-Weiss law $\left(\chi_{\mathrm{m}}=C /(T-\theta)\right)$. Good agreement was found with $C=8.63(1) \mathrm{cm}^{3} \mathrm{~K} \mathrm{~mol}^{-1}$ and $\theta=-0.056(4) \mathrm{K}$. The small $\theta$ value indicates very weak antiferromagnetic exchange coupling between the metal ions. The magnetic moment expected for non-interacting [GdCu] units and $g=2$ is $8.12 \mu_{\mathrm{B}}$, while the observed effective magnetic moment $\mu_{\text {eff }}$ is in the range from $8.18 \mu_{\mathrm{B}}(1.7 \mathrm{~K})$ to $8.23 \mu_{\mathrm{B}}(20 \mathrm{~K})$ with a maximum value of $8.30 \mu_{\mathrm{B}}$ at $8 \mathrm{~K}$ (see Fig. 3a).

The $\mathrm{X}$-ray structure analysis has shown that all separations between $\mathrm{Gd}-\mathrm{Gd}$, 


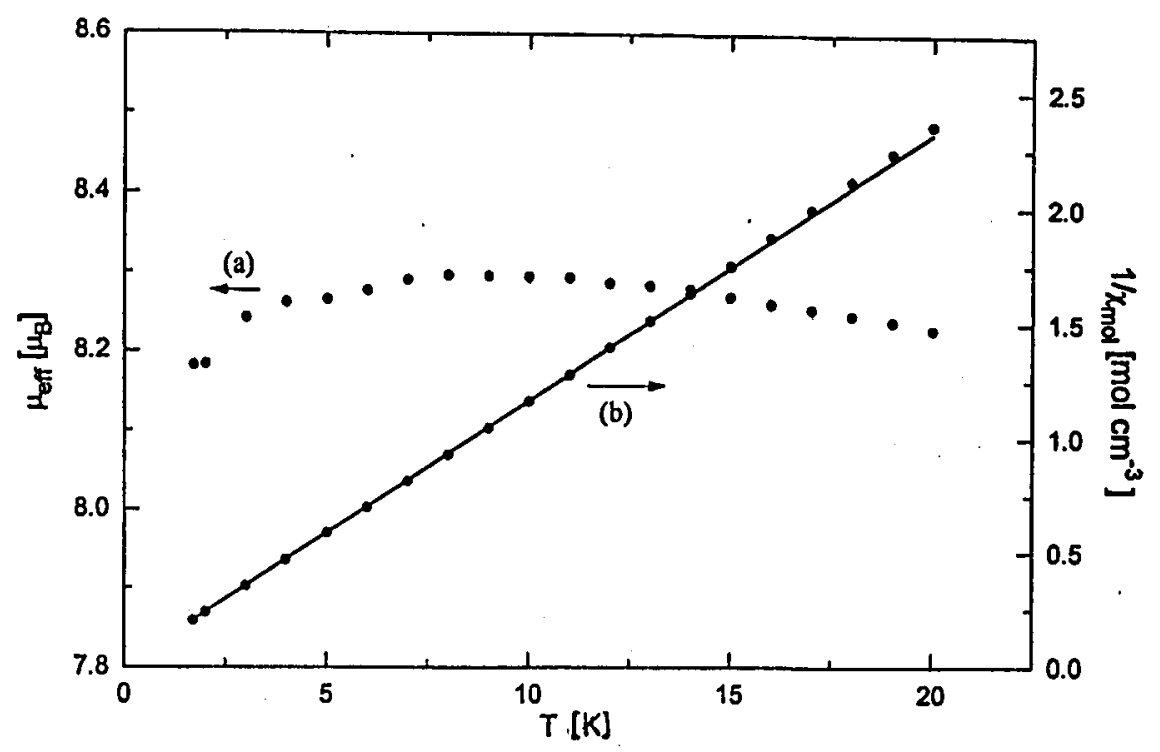

Fig. 3. Temperature dependence of $\mu_{\text {eff }}$ (a) and $1 / \chi^{\prime}$ (b) for $[\mathrm{GdCu}](\bullet$ exp., -- calc.).

$\mathrm{Gd}-\mathrm{Cu}$, and $\mathrm{Cu}-\mathrm{Cu}$ between $[\mathrm{GdCu}]$ units are longer than $8 \AA$. Thus, intermolecular interactions can be neglected. The spin IIamiltonian $\hat{H}=-2 J \hat{S}_{\mathrm{Gd}} \cdot \hat{S}_{\mathrm{Cu}}$ has been used to derive the susceptibility equation $[14,15]$ :

$$
\chi_{\mathrm{m}}=\left(4 N g^{2} \beta^{2} / k T\right)[15+7 \exp (-8 J / k T)] /[9+7 \exp (-8 J / k T)] .
$$

The magnetic susceptibility data of [GdCu] at $0.05 \mathrm{~T}$ have been fitted using this equation, the best fit was obtained with $g=2.046(2), J=-0.039(3) \mathrm{cm}^{-1}$ (see Fig. $3 \mathrm{~b}$ ). The very small negative value of $J$ shows a very weak antiferromagnetic coupling between $\mathrm{Gd}(\mathrm{III})$ and $\mathrm{Cu}(\mathrm{II})$ ions consistent with the negative $\theta$ value. It is worth noting that in the previously investigated $\left[\mathrm{Gd}_{x} \mathrm{Cu}_{y}\right]$ complexes, the bridging ligands contain a conjugated system. In the title compound [GdCu], however, the bridging system has exclusively $\sigma$ bonds. In spite of the rather short $\mathrm{Gd}-\mathrm{Cu}$ separation, the magnitude of $|J|$ for [GdCu] is the smallest one observed so far. This indicates that the nature of bridging ligands is an important factor controlling the magnitude of the spin-spin coupling, in addition to the distance between metal ions and the angle in bridging network. Detailed magnetochemical investigations into $[\mathrm{GdCu}]$ and isostructural $[\mathrm{NdCu}]$ with respect to the temperature and field dependences of the susceptibility are in progress.

\section{Acknowledgment}

Financial support by Deutsche Forschungsgemeinschaft and Fonds der Chemischen Industrie is gratefully acknowledged. S.G. thanks the Alexander von Humboldt Stiftung for a fellowship. 


\section{References}

[1] C. Benelli, A. Caneschi, D. Gatteschi, O. Guillou, L. Pardi, Inorg. Chem. 29, 1750 (1990).

[2] A. Bencini, C. Benelli, A. Caneschi, R.L. Carlin, A. Dei, D. Gatteschi, J. Am. Chem. Soc. 107, 8128 (1985).

[3] A. Bencini, C. Benelli, A. Caneschi, A. Dei, D. Gatteschi, Inorg. Chem. 25, 572 (1986).

[4] M. Andruh, I. Ramade, E. Codjovi, O. Guillou, O. Kahn, J.C. Trombe, J. Am. Chem. Soc. 115, 1822 (1993).

[5] C. Benelli, A.J. Blake, P.E.Y. Milne, J.M. Rawson, R.E.P. Winpenny, Chem. Eur. J. 1, 614 (1995).

[6] O. Guillou, O. Kahn, R.L. Oushoorn, K. Boubekeur, P. Batail, Inorg. Chim. Acta 198-200, 119 (1992).

[7] O. Guillou, P. Bergerat, O. Kahn, E. Bakalbassis, K. Boubekeur, P. Batail, M. Guillot, Inorg. Chem. 31, 110 (1992).

[8] Y.-T. Li, Z.-H. Jiang, S.-L. Ma, X-Y. Li, D.-Z. Liao, S.-P. Yan, G.-L. Wang, Polyhedron 13, 475 (1994).

[9] M.E.M. Hamidi, J.-L. Pascal, Polyhedron 13, 1787 (1994).

[10] P.H. Smith, Z.E. Reyes, C.-W. Lee, K.N. Raymond, Inorg. Chem. 27, 4154 (1988).

[11] E.J. Gabe, Y. Le Page, J.P. Charland, F.L. Lee, P.S. White, J. Appl. Crystallogr. 22, 384 (1989).

[12] S. Wang, Z. Peng, K.D.L. Smith, Y.-S. Ilua, C. Deslippe, M.J. Wagner, Inorg. Chem. 34, 908 (1995).

[13] S. Wang, Z. Pang, K.D.L. Smith, Inorg. Chem. 32, 4992 (1993).

[14] N. Matsumoto, M. Sakamoto, H. Tamaki, II. Okawa, S. Kida, Chem. Lett. 853 (1990).

[15] M. Sakamoto, M. Ilashimura, K. Matsuki, N. Matsumoto, K. Inoue, H. Okawa, Bull. Chem. Soc. Jpn. 64, 3639 (1991). 